\title{
New York State Primary Care Physician Practices and Perspectives on Offering Reproductive Health Services
}

J Gen Intern Med 36(6):1805-7

DOI: $10.1007 / \mathrm{s} 11606-020-06162-\mathrm{w}$

(c) Society of General Internal Medicine 2020

\section{INTRODUCTION}

Primary care provides an important opportunity for patients to access comprehensive reproductive health (RH) services, particularly as reductions to family planning programs continue. ${ }^{1}$ There is a lack of data on the specific RH services provided by primary care physicians (PCPs) and their perceptions of offering these services. ${ }^{2}$ Such information can aid in successfully expanding RH services in primary care. Our objectives were to determine the RH services New York State (NYS) PCPs report providing, their perception of the benefits and disadvantages to providing such services, and which RH services they felt were most important to offer.

\section{METHODS}

We recruited a convenience sample of NYS PCPs through the American Medical Association (AMA) Master File, attendance at two NYS primary care conferences, and staff meetings at two NYS federally qualified health center (FQHC) networks. We describe the recruitment, data collection, and study instrument details, as well as report other findings elsewhere. ${ }^{3,4}$ Our sample was more likely to be female, younger, and specialize in family medicine than the AMA sampling frame.

We conducted chi-squared and one-way ANOVA tests to assess significant differences by specialty in providing any $\mathrm{RH}$ or contraceptive services in the last year, and the mean number of perceived benefits and disadvantages (including barriers) to providing RH services, respectively.

\section{RESULTS}

Half of the physicians in our sample were female. The largest proportion of respondents was aged $42-59(38 \%)$, followed by $36 \%$ aged $24-41$. The majority of respondents provided at least one RH service in the last year (88\%), with HIV/STI testing and counseling (74\%) being the most common,

Received March 18, 2020

Accepted August 14, 2020

Published online September 1, 2020 followed by contraceptive counseling (67\%) and cervical cancer screening (63\%; Table 1). The least reported service provided was induced abortion (9\%). The majority of respondents provided at least one contraceptive method/service (74\%), most notably the pill $(71 \%)$. Eighty-eight percent of family medicine physicians reported providing the pill, compared with $58 \%$ internal medicine providers. However, less than $40 \%$ of PCPs provided any of the other contraceptive services. A significantly larger proportion of family medicine physicians reported providing any RH (97\% vs. $82 \%)$ and contraceptive service ( $91 \%$ vs. $61 \%$ ) in the last year, compared with internal medicine respondents $(p<0.0001)$.

Respondents endorsed an average of 8.4 benefits, from a list of 14 (standard deviation (SD) 4.3, range 0-14; Table 2) associated with providing $\mathrm{RH}$ services in primary care settings, with increased access to RH services (82\%) and patient convenience $(82 \%)$ cited as the most common benefits. On average, respondents endorsed 1.5 disadvantages, from a list of 10 (SD 1.5, range $0-9$ ). The most frequently held perceived disadvantage was not being sufficiently trained $(51 \%)$, cited more often by internal medicine providers (66\%) compared with family medicine respondents (38\%). This was followed by additional time that may detract from other primary care services (32\%); over a third reported no disadvantages (36\%). Family medicine physicians had significantly higher average perceived benefits $(9.8$ vs. $6.7,9.5)$ and fewer disadvantages (1.1 vs. $2.0,1.8)$, compared with internal medicine and other PCPs $(p<0.0001)$. However, the majority of internal medicine providers noted many benefits.

Respondents felt the most important $\mathrm{RH}$ services to add to their clinic were contraceptive counseling (29\%) and cervical cancer screening (29\%), followed by HIV/STI testing and counseling (27\%), all endorsed by more internal medicine respondents.

\section{DISCUSSION}

Although PCPs in our sample offer some RH services, there is room for expansion of comprehensive services. Our findings may reflect differences in RH training by specialty. As compared with internal medicine physician respondents, family medicine physician respondents are already providing more $\mathrm{RH}$ services and may be more comfortable with the prospect of further expanding such services, given recommendations from the American Academy of Family Physicians to integrate such services. ${ }^{5}$ Recognizing the differences in experiences, 
Table 1 Reproductive Health Practices of New York State Primary Care Physician Respondents, 2017

\begin{tabular}{|c|c|c|c|c|}
\hline Variable & $\begin{array}{l}\text { Total } \\
(N=443) \\
n(\%)\end{array}$ & $\begin{array}{l}\text { Family medicine } \\
(n=216) \\
n(\%)\end{array}$ & $\begin{array}{l}\text { Internal medicine } \\
(n=183) \\
n(\%)\end{array}$ & $\begin{array}{l}\text { Other } \\
(n=25) \\
n(\%)\end{array}$ \\
\hline Provided any reproductive health services in the last year*, ${ }^{*}$ & $381(88)$ & $209(97)$ & $148(82)$ & $17(68)$ \\
\hline \multicolumn{5}{|l|}{ Reproductive health services provided in the last year ${ }^{\dagger+}$} \\
\hline HIV/STI testing and counseling & $318(74)$ & $185(86)$ & $115(64)$ & $14(56)$ \\
\hline Contraceptive counseling & $289(67)$ & $185(86)$ & $88(49)$ & $11(44)$ \\
\hline Cervical cancer screening & $270(63)$ & $183(85)$ & $74(41)$ & $11(44)$ \\
\hline Sexual dysfunction counseling & $217(50)$ & $139(64)$ & $66(37)$ & $8(32)$ \\
\hline Routine pregnancy intentions screening & $208(48)$ & $147(68)$ & $51(28)$ & $9(36)$ \\
\hline Preconception care and counseling & $191(44)$ & $143(66)$ & $37(20)$ & $10(40)$ \\
\hline Postpartum care & $111(26)$ & $94(44)$ & $12(7)$ & $5(20)$ \\
\hline Prenatal care & $110(26)$ & $89(41)$ & $17(9)$ & $4(16)$ \\
\hline Infertility evaluation & $109(25)$ & $84(39)$ & $19(11)$ & $5(20)$ \\
\hline Transgender services & $94(22)$ & $70(32)$ & $18(10)$ & $5(20)$ \\
\hline Spontaneous abortion management & $72(17)$ & $63(29)$ & $3(2)$ & $6(24)$ \\
\hline Induced abortion & $40(9)$ & $38(18)$ & $1(1)$ & $1(4)$ \\
\hline None & $51(12)$ & $7(3)$ & $33(18)$ & $8(32)$ \\
\hline Provided any contraceptive services in the last year*,§ & $317(74)$ & $195(91)$ & $108(61)$ & $11(46)$ \\
\hline \multicolumn{5}{|l|}{ Contraceptive services provided in the last year ${ }^{4}, 8$} \\
\hline Birth control pill & $305(71)$ & $190(88)$ & $103(58)$ & $10(42)$ \\
\hline DMPA/Depo-Provera injection & $168(39)$ & $140(65)$ & $20(11)$ & $8(33)$ \\
\hline Emergency contraception & $166(39)$ & $129(60)$ & $29(16)$ & $7(29)$ \\
\hline Distribute male condoms & $159(37)$ & $110(51)$ & $41(23)$ & $7(29)$ \\
\hline Vaginal ring & $120(28)$ & $98(46)$ & $14(8)$ & $7(29)$ \\
\hline IUD removal & $104(24)$ & $93(43)$ & $5(3)$ & $6(25)$ \\
\hline IUD insertion & $92(22)$ & $77(36)$ & $9(5)$ & $6(25)$ \\
\hline Implant insertion & $71(17)$ & $67(31)$ & $2(1)$ & $2(8)$ \\
\hline Implant removal & $67(16)$ & $63(29)$ & $1(1)$ & $3(13)$ \\
\hline Distribute female condoms & $58(14)$ & $42(20)$ & $11(6)$ & $5(21)$ \\
\hline Diaphragm & $31(7)$ & $25(12)$ & $5(3)$ & $1(4)$ \\
\hline Female sterilization/tubal ligation & $20(5)$ & $14(7)$ & $4(2)$ & $2(8)$ \\
\hline Vasectomy & $19(5)$ & $14(7)$ & $5(3)$ & $0(0)$ \\
\hline None & $110(26)$ & $20(9)$ & $70(39)$ & $13(54)$ \\
\hline
\end{tabular}

$* p<0.0001$

$n=11$ missing

${ }^{t}$ Percentages sum to greater than 100 as respondents were able to choose more than 1 response

${ }_{n}=16$ missing

Table 2 New York State Primary Care Physician Respondent Perceptions of Reproductive Health Services, 2017

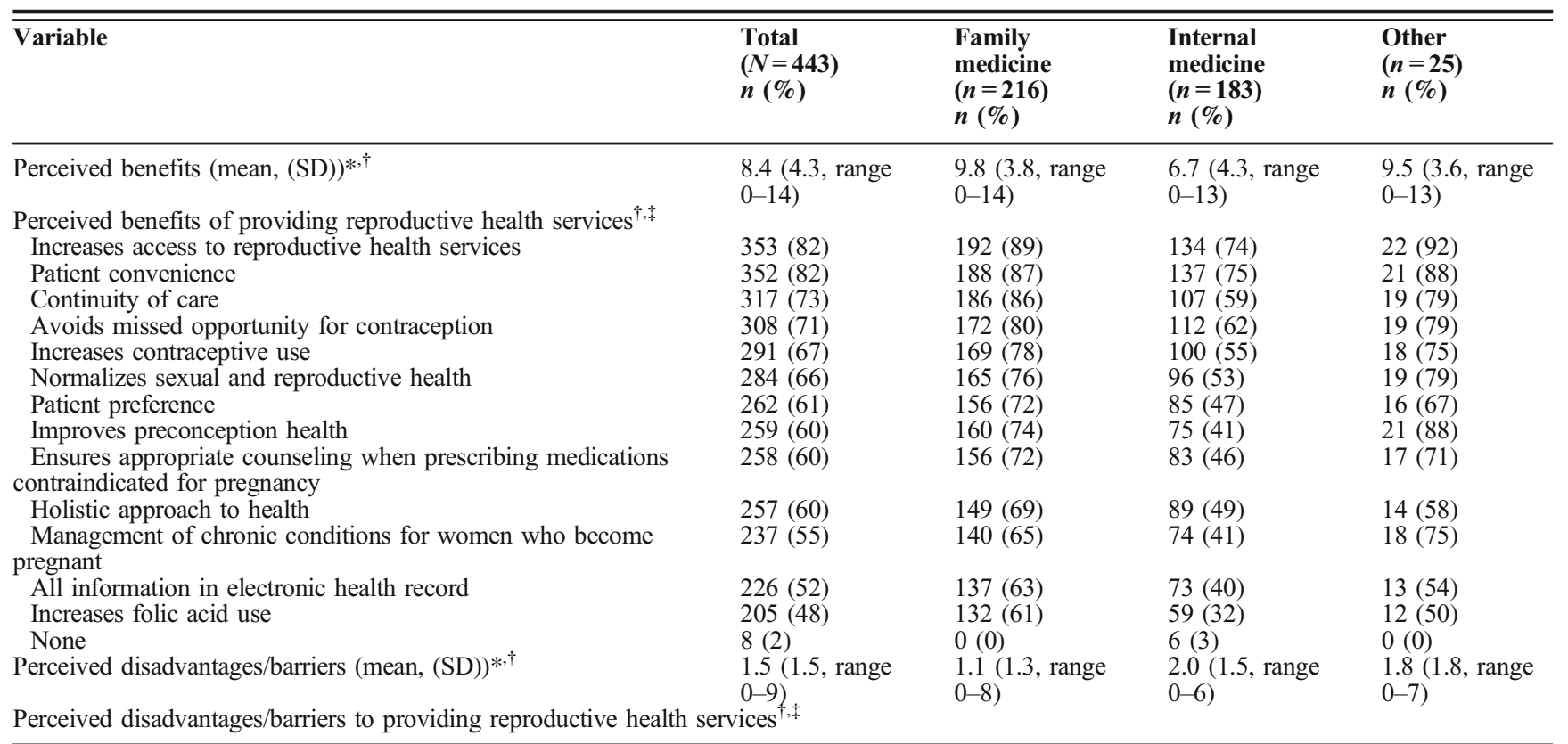


Table 2. (continued)

\begin{tabular}{|c|c|c|c|c|}
\hline Variable & $\begin{array}{l}\text { Total } \\
(N=443) \\
n(\%)\end{array}$ & $\begin{array}{l}\text { Family } \\
\text { medicine } \\
(n=216) \\
n(\%)\end{array}$ & $\begin{array}{l}\text { Internal } \\
\text { medicine } \\
(n=183) \\
n(\%)\end{array}$ & $\begin{array}{l}\text { Other } \\
(n=25) \\
n(\%)\end{array}$ \\
\hline Not well trained & $218(51)$ & $81(38)$ & $120(66)$ & $13(54)$ \\
\hline Additional time (detracts from other primary care services) & $138(32)$ & $47(22)$ & $78(43)$ & $9(38)$ \\
\hline Unclear reimbursement/billing & $98(23)$ & $45(21)$ & $46(25)$ & $5(21)$ \\
\hline May not be patient preference & $69(16)$ & $21(10)$ & $40(22)$ & $6(25)$ \\
\hline Discomfort with reproductive health discussions & $37(9)$ & $12(6)$ & $20(11)$ & $4(17)$ \\
\hline Not within the primary care scope of practice & $32(7)$ & $1(1)$ & $28(15)$ & $2(8)$ \\
\hline Reduces support for stand-alone reproductive health clinics & $20(5)$ & $6(3)$ & $11(6)$ & $2(8)$ \\
\hline Stigma & $18(4)$ & $8(4)$ & $7(4)$ & $2(8)$ \\
\hline Detracts from patient-centered care & $6(1)$ & $1(1)$ & $4(2)$ & $0(0)$ \\
\hline None & $154(36)$ & $98(45)$ & $43(24)$ & $8(33)$ \\
\hline \multicolumn{5}{|l|}{ Most important reproductive health service to add $\$, \S$} \\
\hline Contraceptive counseling & $120(29)$ & $43(21)$ & $71(40)$ & $5(20)$ \\
\hline Cervical cancer screening & $119(29)$ & $43(21)$ & $69(39)$ & $6(24)$ \\
\hline HIV/STI testing and counseling & $113(27)$ & $34(16)$ & $72(41)$ & $6(24)$ \\
\hline Transgender services & 79 (19) & $47(22)$ & $28(16)$ & $3(12)$ \\
\hline All services already provided & 78 (19) & $57(27)$ & $14(8)$ & $7(28)$ \\
\hline Sexual dysfunction counseling & $76(18)$ & $28(13)$ & $41(23)$ & $6(24)$ \\
\hline Routine pregnancy intentions screening & $72(17)$ & $26(12)$ & $44(25)$ & $2(8)$ \\
\hline Preconception care and counseling & $67(16)$ & 27 (13) & $38(21)$ & $2(8)$ \\
\hline Prenatal care & $50(12)$ & $23(11)$ & $23(13)$ & $3(12)$ \\
\hline Infertility evaluation & $39(9)$ & $20(10)$ & $15(8)$ & $4(16)$ \\
\hline Postpartum care & $32(8)$ & $15(7)$ & $14(8)$ & $2(8)$ \\
\hline Induced abortion & $27(7)$ & $17(8)$ & $6(3)$ & $4(16)$ \\
\hline Spontaneous abortion management & $26(6)$ & $20(10)$ & $5(3)$ & $1(4)$ \\
\hline None & 57 (14) & $32(15)$ & $18(10)$ & $5(20)$ \\
\hline
\end{tabular}

$* p<0.0001$

${ }^{*} n=11$ missing

${ }^{7}$ Percentages sum to greater than 100 as respondents were able to choose more than 1 response

${ }^{\delta_{n}}=27$ missing

perspectives, and current scope of practice by PCP training is important when considering changes in practice protocols. Training on RH service delivery, particularly for internal medicine physicians, may be needed prior to implementation. As this is a convenience sample, our findings cannot be generalized to PCPs in NYS or elsewhere. Some respondents recruited at conferences may have been sub-specialists. Nonetheless, given the receptivity to providing $\mathrm{RH}$ care across subspecialties, this study can inform administrators, clinicians, and educators considering expansion of $\mathrm{RH}$ services in primary care.

Meredith G. Manze, $\mathrm{MPH}, \mathrm{PhD}^{1}$

Heidi E. Jones, $M P H, P h D^{1}$

Lynn Roberts, $\mathrm{PhD}^{1}$

Susan E. Rubin, $M D, M P H^{2}$

Diana R. Romero, MA, $P h D^{1}$

${ }^{1}$ Graduate School of Public Health and Health Policy, City University of New York (CUNY),

New York, NY, USA

${ }^{2}$ Institute for Family Health,

New York, NY, USA

Corresponding Author: Meredith G. Manze, MPH, PhD; Graduate School of Public Health and Health Policy, City University of New York (CUNY) New York, NY, USA (e-mail: Meredith.manze@sph.cuny.edu).
Funding This research was funded by the Society for Family Planning Research Fund (\#SFPRF10-II2-5). The funding source was not involved in the study design; in the collection, analysis, and interpretation of data; in the writing of the report; or in the decision to submit the article for publication. The views and opinions expressed are those of the authors and do not necessarily represent the views and opinions of SFPRF.

\section{Compliance with Ethical Standards:}

Conflict of Interest: The authors declare that they do not have no a conflict of interest.

\section{REFERENCES}

1. Zolna M, Finn S, Frost J. Estimating the impact of changes in the Title $\mathrm{X}$ network on patient capacity. Guttmacher Institute. February 5, 2020. https://www.guttmacher.org/article/2020/02/estimating-impactchanges-title-x-network-patient-capacity. Accessed May 11, 2020.

2. Bello JK, Rao G, Stulberg DB. Trends in contraceptive and preconception care in United States ambulatory practices. Fam Med. 2015;47(4):264271.

3. Manze M, Calixte C, Romero D, et al. Physician perspectives on routine pregnancy intention screening and counseling in primary care. Contraception. 2020;101(2):91-96.

4. Jones H, Calixte C, Manze M, et al. Primary care patients' preferences for reproductive health service needs assessment and service availability in New York Federally Qualified Health Centers. Contraception. 2020;101(4):226-230.

5. American Academy of Family Physicians. Summary of recommendations for clinical preventive services. July 2017; Order No. 1968.

Publisher's Note: Springer Nature remains neutral with regard to jurisdictional claims in published maps and institutional affiliations. 